\title{
Influence of bed deposit in the prediction of incipient sediment motion in sewers using artificial neural networks
}

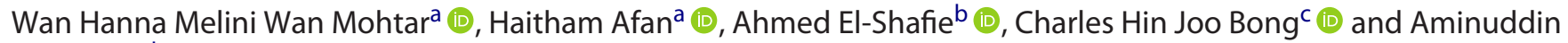 \\ Ab. Ghanid \\ aDepartment of Civil \& Structural Engineering, Faculty of Engineering and Built Environment, Universiti Kebangsaan Malaysia, Bandar Baru Bangi, \\ Malaysia; ${ }^{b}$ Department of Civil Engineering, Faculty of Engineering, Universiti Malaysia, Kuala Lumpur, Malaysia; ${ }^{\mathrm{C}}$ Department of Civil Engineering, \\ Faculty of Engineering, Universiti Malaysia Sarawak, Kota Samarahan, Malaysia; ${ }^{d}$ River Engineering and Urban Drainage Research Centre (REDAC), \\ Universiti Sains Malaysia, Nibong Tebal, Malaysia
}

\begin{abstract}
This study investigates the performance of artificial neural networks in predicting the incipient sediment motion in sewers. Two neural network algorithms, i.e. feed forward neural network (FFNN) and radial basis function (RBF), were employed to estimate the critical velocity over varying sediment thickness, median grain size and water depth. Empirical data from five studies were fed into the models and the performance of each model was scrutinized based on three performance criteria. Prediction from FFNN was found to give higher accuracy than values obtained from RBF. Analysis was also extended to observe the correlation between the predicted critical velocity $V_{c p}$ with calculated critical velocity $V_{c m}$ using five empirical equations developed using non-linear regression analysis. Prediction by FFNN proved to have the highest accuracy compared to the RBF and the values obtained through empirical equations described in this study.
\end{abstract}

\section{ARTICLE HISTORY}

Received 28 March 2017

Accepted 17 March 2018

\section{KEYWORDS}

Incipient sediment motion; sewers; sediment bed thickness; artificial neural networks

\section{Introduction}

The determination of mobility state for a particle grain from its previous stationary position is essential in modelling water streams. This condition is known as the incipient sediment motion or threshold criteria of sediment movement and is often described as the critical Shields parameter $\theta_{c}$. This parameter was famously developed by Shields (1936), represented as

$$
\theta_{c}=\frac{\tau_{c}}{\left(\rho_{s}-\rho\right) g d}
$$

where $\tau_{c}=\rho v_{* c}^{2}$ is the critical bed shear stress, $v_{* c}$ is the critical shear velocity, i.e. a characteristic velocity defined at the nearbed region, $\boldsymbol{d}$ is the mean grain diameter and $\rho_{s}$ and $\rho$ are the sediment and fluid densities, respectively.

Using extrapolation for sediment incipient motion, Shields (1936) developed the well established Shields diagram using homogeneous particles on a loose boundary condition. Since then, numerous empirical equations have been put forward and improved the representation of Shields curve (Buffington and Montgomery 1997). Engineering practitioners have used either Shields diagram or empirical equations to obtain the critical velocity $V_{c}$ (through the representation from critical shear velocity $v_{* c}=\sqrt{\tau_{c} / \rho}$ ) of particles for calculations including drainage design, determination of self-cleansing velocity, and erosion protection, to name a few.

The presence of sediment in sewerage pipes and urban drainage is found to be substantial (Tait, Rushforth, and Saul 1998; Bong et al. 2016). Theoretically, when the flow velocity is considerably lower than the critical velocity, the sediment tends to be deposited and, over time, accumulates to a certain depth. However, it has been found that particles can move even slower than the flow velocity, even in the flow condition where deposition is not expected (Ota and Perrusquía 2013). Efficient sewer design therefore needs to consider the threshold condition for incipient deposition, whereby at a certain flow condition and sewer shape, the probability of sediment deposition may be predicted (Safari, Aksoy, and Mohammadi 2015, 2016). Transport at the limit of sediment deposition, which serves as the basis of the self-cleansing sewer concept, is described in the works of Ota and Nalluri (2003). With the help of artificial intelligence, the minimum mean flow velocity to avoid deposition can be predicted to a reasonable degree of accuracy based on the particle Froude number for various sewer shapes (Ebtehaj et al. 2016; Safari et al. 2017).

In the time of dry seasons with low flow, the conditions promote long-term deposition, whereby the deposited sediment changes in surface roughness and increases in hydraulic resistance, affecting the velocity distribution and reducing the flow capacity (Banasiak et al. 2005). The deposited sediment in sewerage pipes or sewers may have thickness $t_{s}$ less than $10 \mathrm{~mm}$ or up to $100 \mathrm{~mm}$ (Ashley et al. 1992). For storm-water drains, the deposition thickness can be as high as $330 \mathrm{~mm}$ (Bong, Lau, and Ghani 2014).

The sediment found in the sewerage pipes is known as 'insewer sediment'. The characteristics of the sediment mixture can vary due to presence of both organic and inorganic particles (from the waste-water). High organic content promotes the formation of a bio-film on the accumulated sediment, particularly on a stable sediment bed surface (VollertsenVollertsen and 